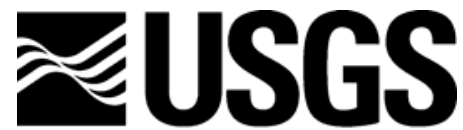

science for a changing world

In Collaboration with U.S. Fish and Wildlife Service

\title{
Advancing Migratory Bird Conservation and Management by Using Radar: An Interagency Collaboration
}

By Janet M. Ruth, Wylie C. Barrow, Richard S. Sojda, Deanna K. Dawson, Robert H. Diehl, Albert Manville, Michael T. Green, David J. Krueper, and Scott Johnston

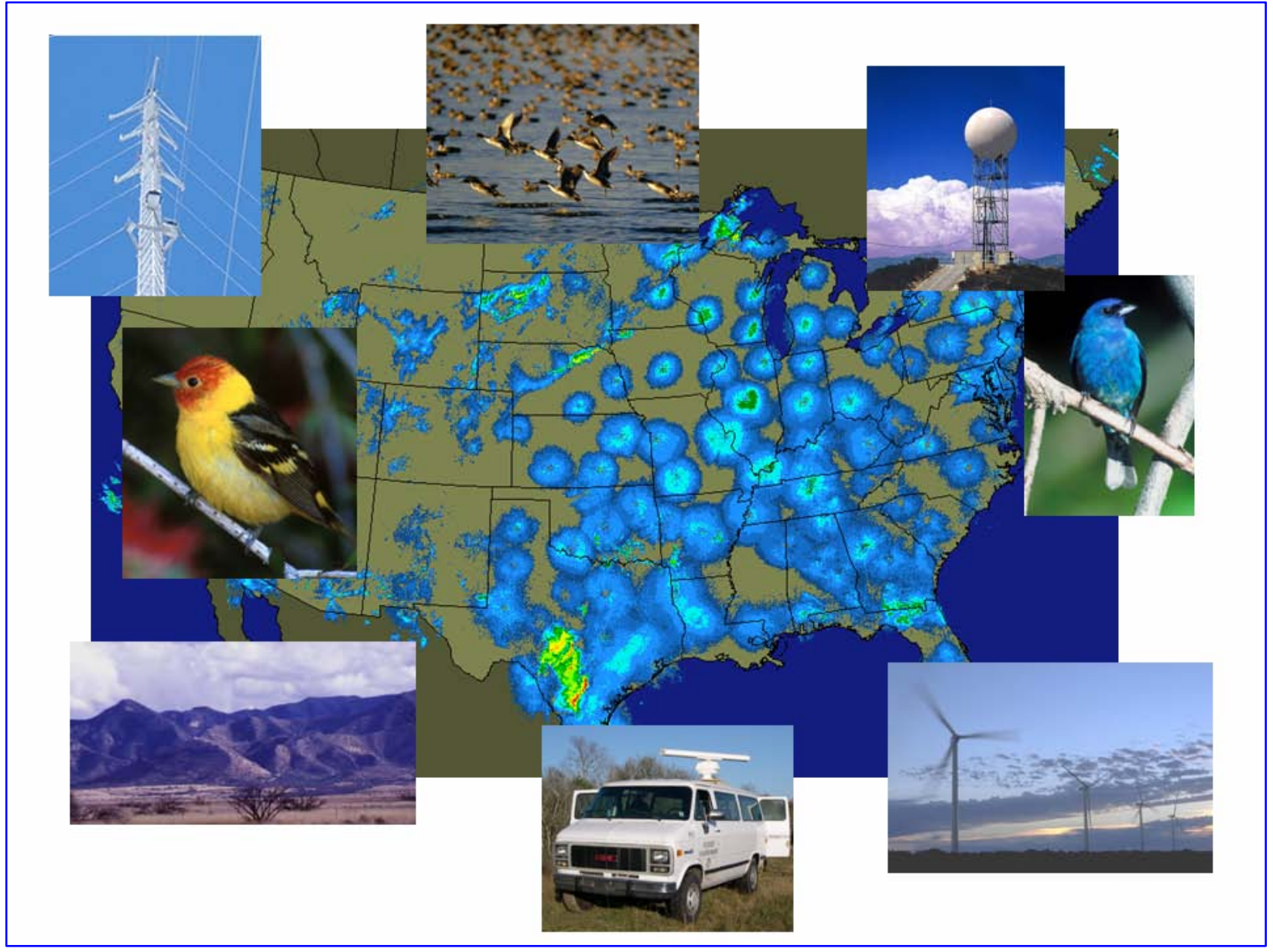

Open-File Report 2005-1173

U.S. Department of the Interior

U.S. Geological Survey 


\section{U.S. Department of the Interior \\ Gale A. Norton, Secretary}

\section{U.S. Geological Survey \\ Charles G. Groat, Director}

U.S. Geological Survey, Reston, Virginia 2005

For product and ordering information:

World Wide Web: http://www.usgs.gov/pubprod

Telephone: 1-888-ASK-USGS

For more information on the USGS - the Federal source for science about the Earth, its natural and living resources, natural hazards, and the environment:

World Wide Web: http://www.usgs.gov

Telephone: 1-888-ASK-USGS

Suggested citation:

Ruth, J.M., Barrow, W.C., Sojda, R.S., Dawson, D.K., Diehl, R.H., Manville, A., Green, M.T., Krueper, D.J., and Johnston, S., 2005, Advancing migratory bird conservation and management by using radar: An interagency collaboration: U.S. Geological Survey, Biological Resources Discipline, Open-File Report 2005-1173, 12 p.

Any use of trade, firm, or product names is for descriptive purposes only and does not imply endorsement by the U.S. Government

Although this report is in the public domain, permission must be secured from the individual copyright owners to reproduce any copyrighted material contained within this report. 


\section{Contents}

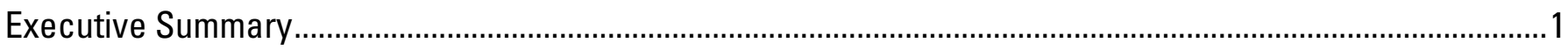

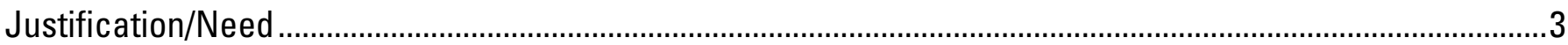

Radar Technologies: Biological Applications ……………..........................................................................

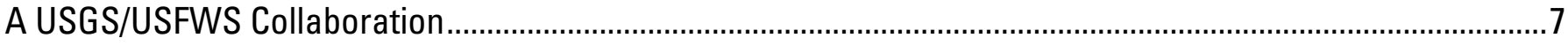

Current USGS Research Using Radar Data .................................................................................................

What Does the Future Hold?

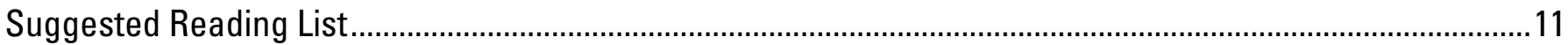

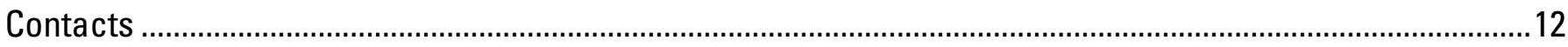

\section{Figures}

Figure 1. Distribution of Doppler weather radar stations across the continental United States....................... 4

Figure 2. Radar captures this snapshot of bird migration across the central United States. .............................5

Figure 3. Songbirds initiate southward migration throughout the northern lower peninsula of Michigan .......6

Figure 4. At the onset of migration, waterfowl depart cooling lakes and reservoirs along the Illinois River ...6 


\section{Advancing Migratory Bird Conservation and Management by Using Radar: An Interagency Collaboration}

By Janet M. Ruth, Wylie C. Barrow, Richard S. Sojda, Deanna K. Dawson, Robert H. Diehl, Albert Manville, Michael T. Green, David J. Krueper, and Scott Johnston

\section{Executive Summary}

Migratory birds face many changes to the landscapes they traverse and the habitats they use. Wind turbines and communications towers, which pose hazards to birds and bats in flight, are being erected or proposed across the United States and offshore. Human activities can also destroy or threaten habitats critical to birds during migratory passage, and climate change appears to be altering migratory patterns. The U.S. Fish and Wildlife Service (USFWS) and other agencies are under increasing pressure to identify and evaluate movement patterns and habitats used during migration and other times.

Few tools for deciphering migratory travels exist, but radar-based studies of movements and habitat use patterns in songbirds, waterfowl, and bats hold promise. The U.S. system of over 150 Doppler weather radars provides continental coverage, similar to the scale of bird migration. Although data stored from weather radar represent perhaps the second largest biological data archive in the world, use of those data is currently limited to technically savvy biologists who can handle the obscure data formats. Complementary mobile radar units and thermal and acoustic monitoring are also used in site-specific studies. Efforts to advance bird conservation and management through the use of radar arose independently in several USFWS/USGS collaborations. Recently, this coalition of scientists and resource managers identified the need to work together more closely to foster radar-related research and software development.

U.S. Geological Survey (USGS) scientists at Fort Collins Science Center, National Wetlands Research Center, Northern Rocky Mountain Science Center, and Patuxent Wildlife Research Center, as well as USFWS Migratory Bird biologists across the country, are collaborating with university partners to develop a suite of products for managers. The goals are to identify migratory pathways and stopover sites for conservation, mitigation, and landscape planning; convey the importance of functional landscapes and unobstructed airspaces for migrating wildlife; enable use of radar by the wider biological, wind power, and related communities; and simplify the analysis of radar data. The long term focus is to use radar technologies to better understand movement patterns and habitat associations of migratory birds and other wildlife. Land managers and industry may use the knowledge and tools developed to optimize the siting of energy projects, other facilities, and migratory bird habitat projects.

Affiliations for authors are listed in "Contacts" at the end of the report. 
The complementary endeavors, not all of which are funded, concentrate on four fundamentals: (1) develop software, in collaboration with National Oceanic and Atmospheric Administration (NOAA) scientists, that enables biologists to access unfiltered weather data and integrate it into standard geographic information systems; (2) develop artificial intelligence-based filters that separate bird from nonbird radar echoes; (3) determine characteristics of bird migration in terms of altitude, speed and direction, daily movements, seasonality, and associations with habitats and landforms; and (4) examine specific movement patterns in relation to towers, wind generation facilities, and tall obstructions.

Many technical issues make this work difficult, including complex data structures, massive data sets, digital recognition of birds, large areas not covered by weather radar, and model validation; however, progress will only be furthered by tackling the challenge. The new coalition will meets its goals by: (1) facilitating a productive collaboration with NOAA, Department of the Interior bureaus, state wildlife agencies, universities, power companies, and other potential partners; (2) building and strengthening scientific capabilities within USGS; (3) addressing key migratory bird management issues; and (4) ensuring full funding for the collaborative effort.

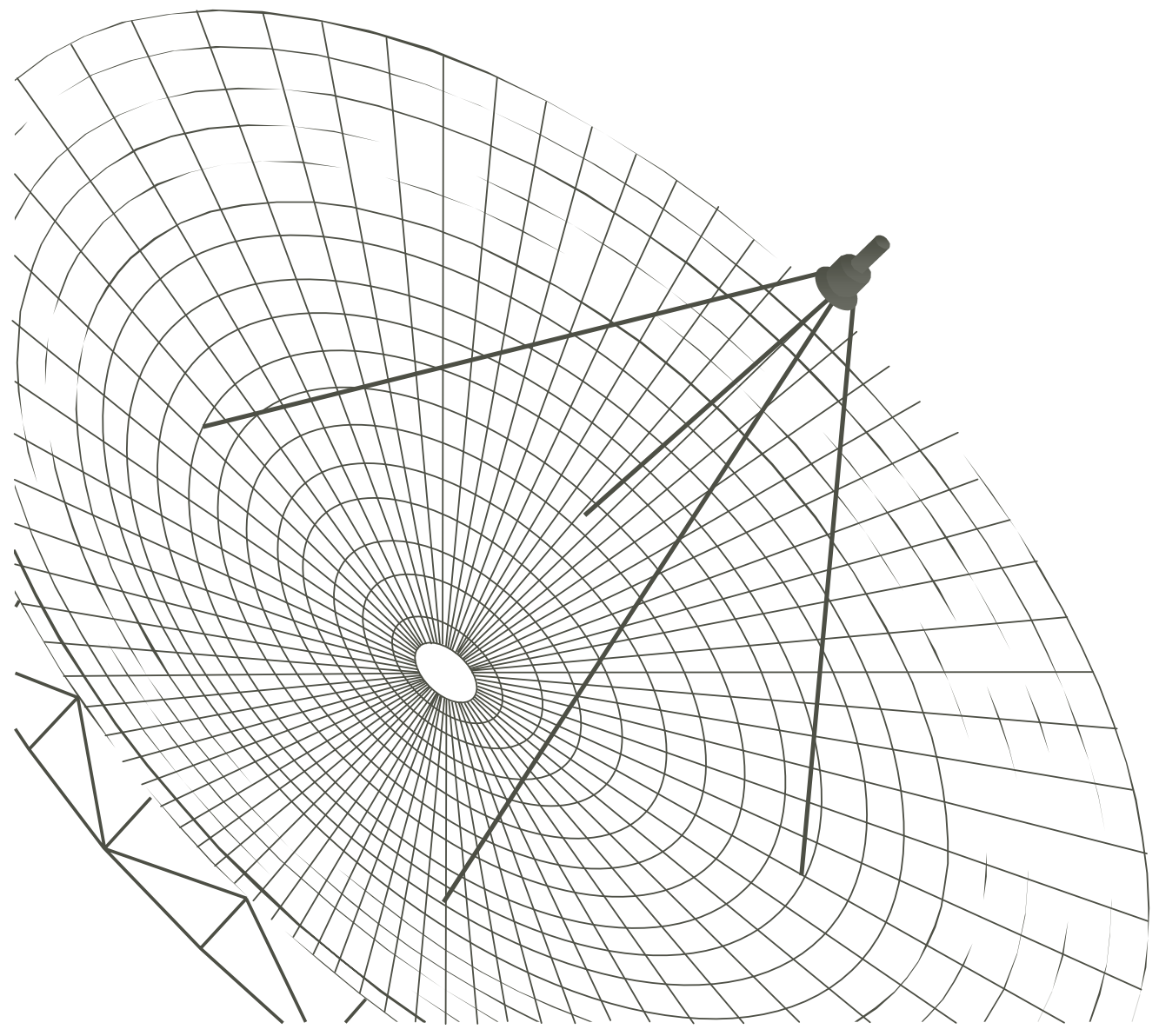




\section{Justification/Need}

The U.S. Geological Survey (USGS) and the U.S. Fish and Wildlife Service (USFWS) are working together to address strategic scientific challenges that will affect resource management capabilities in the next 15-20 years through joint initiatives like Future Challenges. The importance of one of these challenges--implementation of bird conservation actions across North America--is demonstrated by recent activities and accomplishments such as the establishment of the North American Bird Conservation Initiative (NABCI), the development of $\boldsymbol{A}$ Blueprint for the Future of Migratory Birds, the USFWS strategic plan for migratory bird conservation, and the production of a series of updated plans for the major bird conservation initiatives: the Partners in Flight North American Landbird Conservation Plan (2004), the 2004 Strategic Guidance document for the North American Waterfowl Management Plan, the United States Shorebird Conservation Plan, $2^{\text {nd }}$ Edition (2001), and Waterbird Conservation for the Americas, Version 1 (2002). Increasingly, the issues faced by resource managers require the ability to address bird conservation issues at the landscape scale rather than at local, site-specific scales. In addition, there are many areas of the country where traditional, on-the-ground field work is logistically infeasible: the expenses of getting people on the ground are too high; the habitats are too remote and/or inhospitable; or access is limited. Means of addressing conservation needs in an efficient, costeffective manner under such challenging circumstances are desperately needed.

There is a continuing need among resource management agencies to understand human impacts on migratory bird populations beyond the natural challenges faced during migration (e.g., high energy demands, competition, predation, severe weather). Several bat species also undertake substantial migrations, posing similar conservation concerns. Understanding how migrants use habitats through all three phases of the life cycle--breeding, wintering, and migration--is critical to any species conservation plan. Habitats and other resources critical to birds during migratory passage and stopover are being destroyed and threatened by human activities; however, birds and bats are also uniquely susceptible to human use of the airspace. Wind power projects, communication towers, and other tall structures, known to cause bird and bat mortality, are being erected or proposed across the United States and offshore. Resource managers currently lack the information needed to fully assess the potential impacts of these structures on populations of migrating birds and bats. Additionally, across the continent, migrants face a variety of potential barriers in their passages north and south, including the Gulf of Mexico, the western Atlantic, the Great Lakes, the arid landscapes of the Southwest, and the Rocky and Appalachian mountain ranges. Understanding how migrants respond to these barriers and other geographic features (e.g., coastal woodlands and riparian corridors) is crucial to the conservation of these species and their habitats. There is a growing consensus among land managers and conservation organizations (e.g., USFWS, Partners in Flight [PIF], NABCI, The Nature Conservancy, Bat Conservation International) that focusing our attentions at the landscape level in addressing these issues is critical to conservation of migratory species.

The biological data available from the nationwide network of Doppler weather radars present a unique opportunity to learn more about the spatiotemporal distribution patterns, flight characteristics, and habitat use of migrating birds and bats over large regions. These data provide the broad-based context for understanding local or site-based migration research results and can aid in directing future field-based research to identify the locations and relative importance of habitats used by passage migrants. In spite of the many possible applications of biological radar data to migratory species management or conservation questions, few biologists possess the necessary expertise (e.g., Dr. Ron Larkin, Dr. Sid Gauthreaux, and their students). Collaborative efforts 
among USGS, USFWS, and other management and research partners will enable them to answer priority research questions posed by resource management agencies about different taxa including landbirds, shorebirds, wading birds, waterfowl, raptors, bats, and insects. The information developed will assist managers in protecting migratory species, managing habitats, enforcing laws, evaluating permit applications, minimizing negative impacts, and planning for future environmental change.

\section{Radar Technologies: Biological Applications}

One of the few current technologies that allows spatiotemporally comprehensive sampling of large-scale biological phenomena is the national Doppler weather radar system, with its greater than 1 million gigabyte data archive (likely the world's second largest biological archive, containing up to 13 years of data). This system offers tremendous untapped potential as a biological tool for studies of "aerofauna" and their ecological interactions with the environment.

Radars transmit an electromagnetic energy pulse into the atmosphere and then listen for returned signals. When a transmitted pulse strikes a target (e.g., raindrops, birds, insects), the energy is scattered but a small amount is reflected back towards the radar as an "echo." In general, the strength of the echo increases with the number and size of targets and can be used to estimate the number of objects in the atmosphere. Recent advances in radar technology in the United States, particularly the commissioning of a system of more than 150 digital Doppler weather surveillance radars, have considerably increased the range of biological applications for radar. This nationwide system (fig. 1) is owned by the National Oceanic \& Atmospheric Administration's (NOAA) National Weather Service, the Federal Aviation Administration, and the Department of Defense. The Doppler weather radar system boasts numerous advances over its predecessors, including greater sensitivity to weak echoes and higher spatial resolution. Because the radars are Doppler capable, they are able to measure the direction and speed of targets as they move toward and away

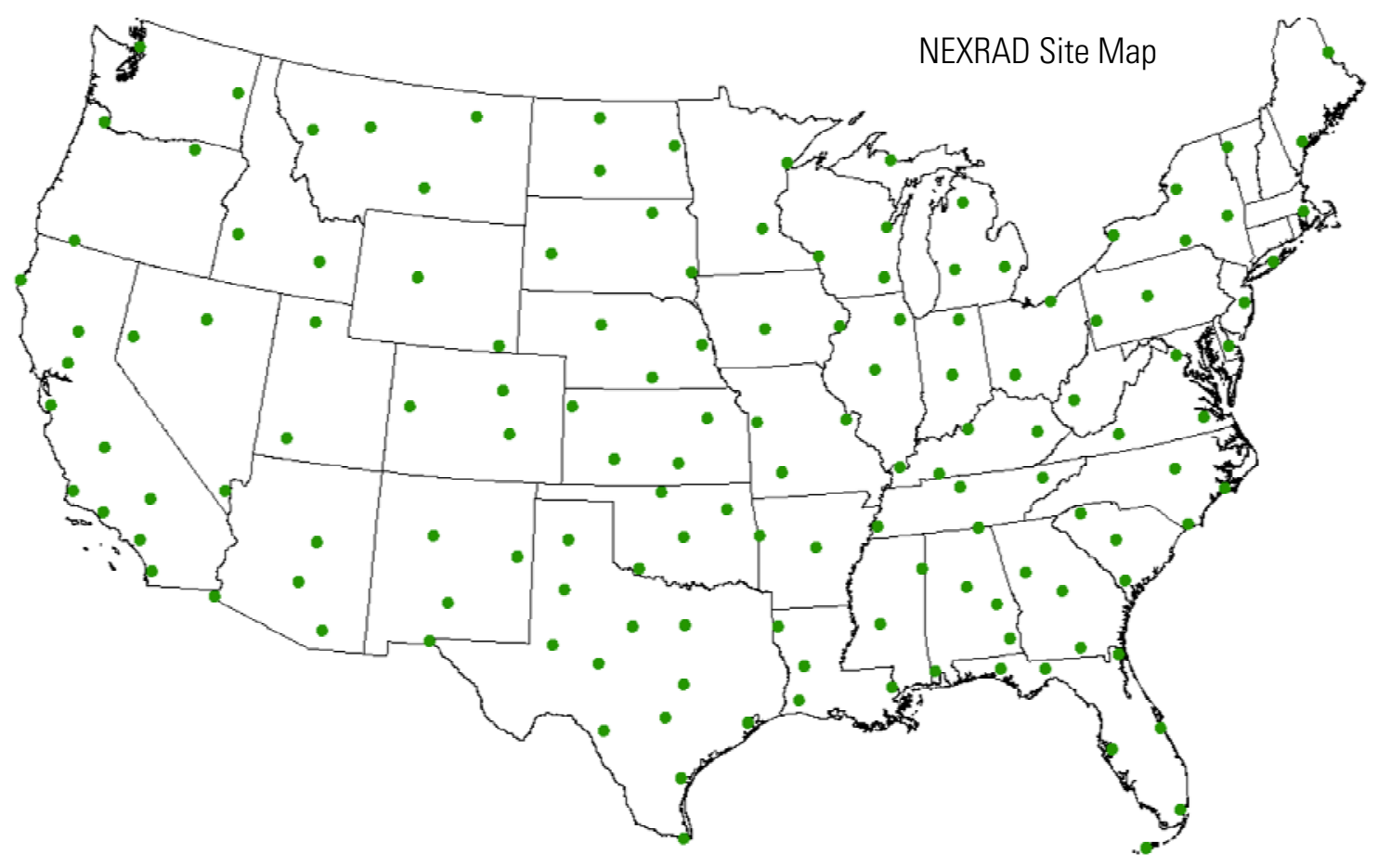

Figure 1. Distribution of Doppler weather radar stations across the continental United States. 
from the radar. Doppler information also aids in distinguishing among certain kinds of biological targets. However, the greatest advance is the generation and availability of digital data which, coupled with the widespread availability of inexpensive computing power, opens an enormous range of quantitative biological applications. External users have free access to these data through NOAA, either in real-time or through a network-accessible archive maintained by NOAA's National Climatic Data Center in Asheville, NC.

Over the last five decades, radar has been used primarily as a tool in studies of migratory biology. Radar can record data on density, direction, speed, altitude, and heading of animals aloft (fig. 2). In addition, as birds and bats initiate flight either to continue migrating or to make local movements, these exoduses from stopover habitat are easily detected by radar (figs. 3 and 4). With the aid of geographic information systems (GIS) to provide geospatial data on land cover and topography, exodus data allow us to identify the locations, types, and extent of use of important habitats (e.g., figs. 3 and 4 ) at a range of scales (from the patch to the continent), as well as to measure birds' responses to geographic features (e.g., oceans, mountains, deserts). A variety of radars, from low-powered airport surveillance radars and mobile marine surveillance radars to high-powered weather radars and military tracking radars, have been used to further our understandings of bird migration and to address conservation concerns. Site-specific information on migrant passage rates and flight characteristics is generally collected by using mobile radars or other techniques (e.g., thermal imaging, acoustical monitoring). Examples provided here are primarily from research on landbird migration in the eastern and central United States, but the technologies also apply to other wildlife (e.g., waterfowl, raptors, bats; fig. 4), to local movements, and to other regions of the country.

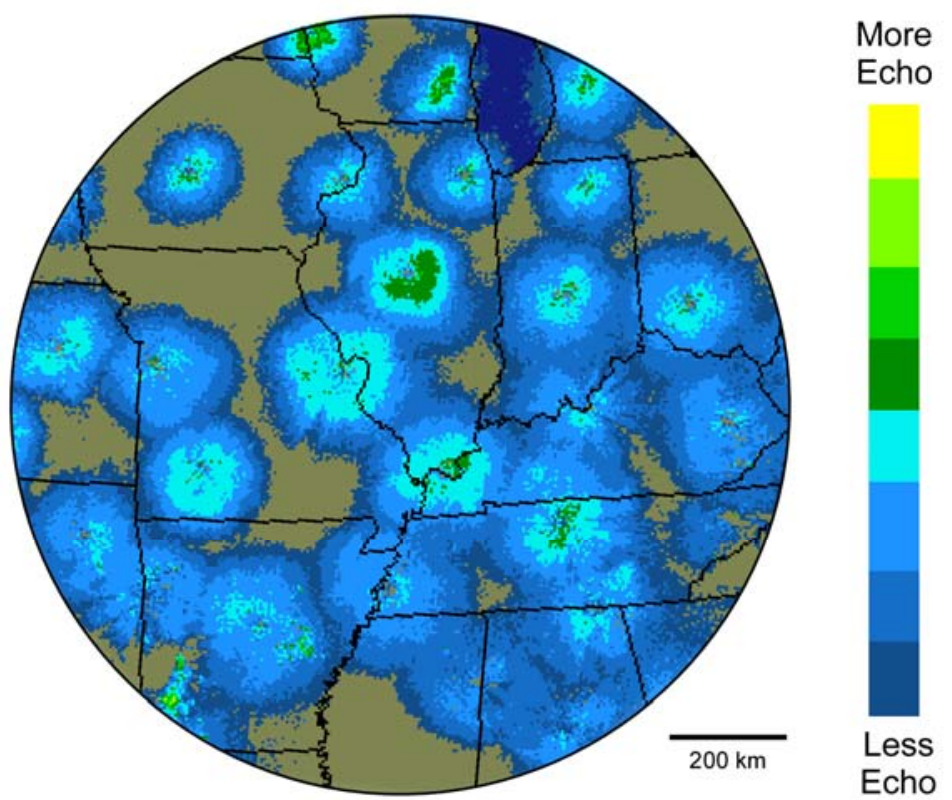

Figure 2. Radar captures a snapshot of bird migration across the central United States on April 28, 2004, at 23:02 CDT. Individual radars detect birds out to a certain range shown as circular patterns of echoes. The overall pattern indicates that birds are migrating as a relatively continuous layer. No substantial large-scale structure appears in this layer; birds are migrating everywhere. 


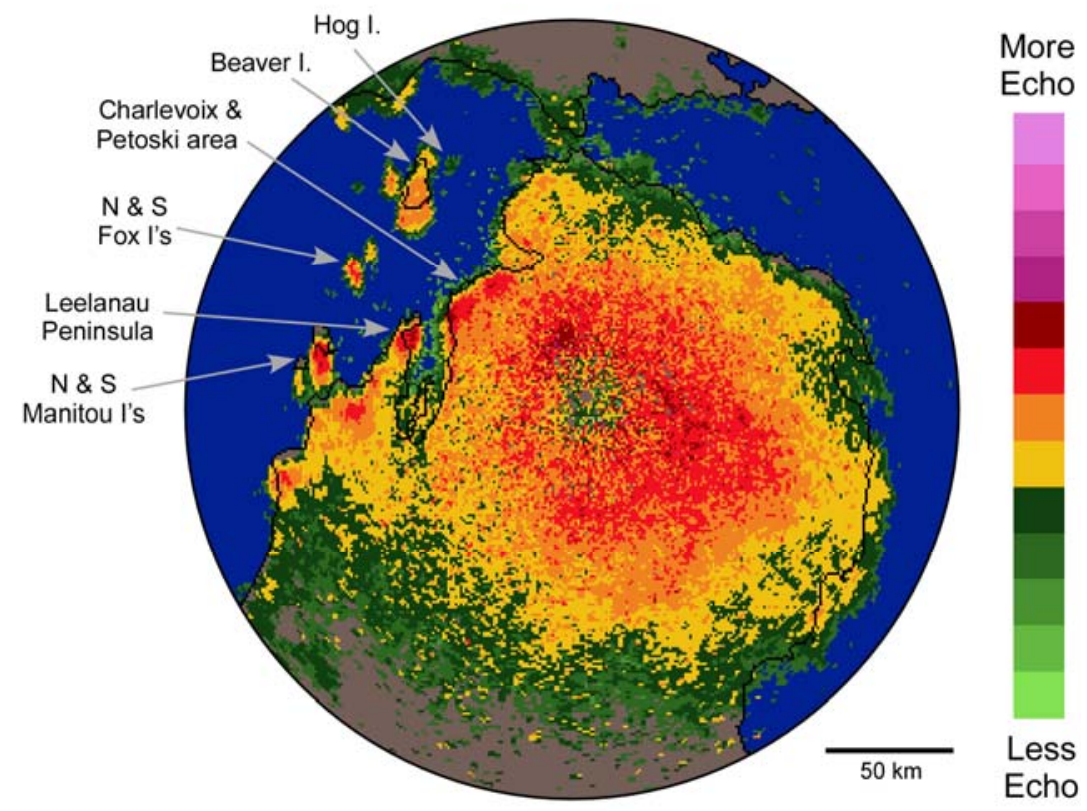

Figure 3. Songbirds initiate southward migration throughout the northern lower peninsula of Michigan on August 15, 2000, at 8:31 p.m. CDT. Radar echoes show birds concentrated in coastal habitats near Charlevoix, Petoski, and Leelanau. Departures from numerous islands in northern Lake Michigan (labeled) are clearly visible.

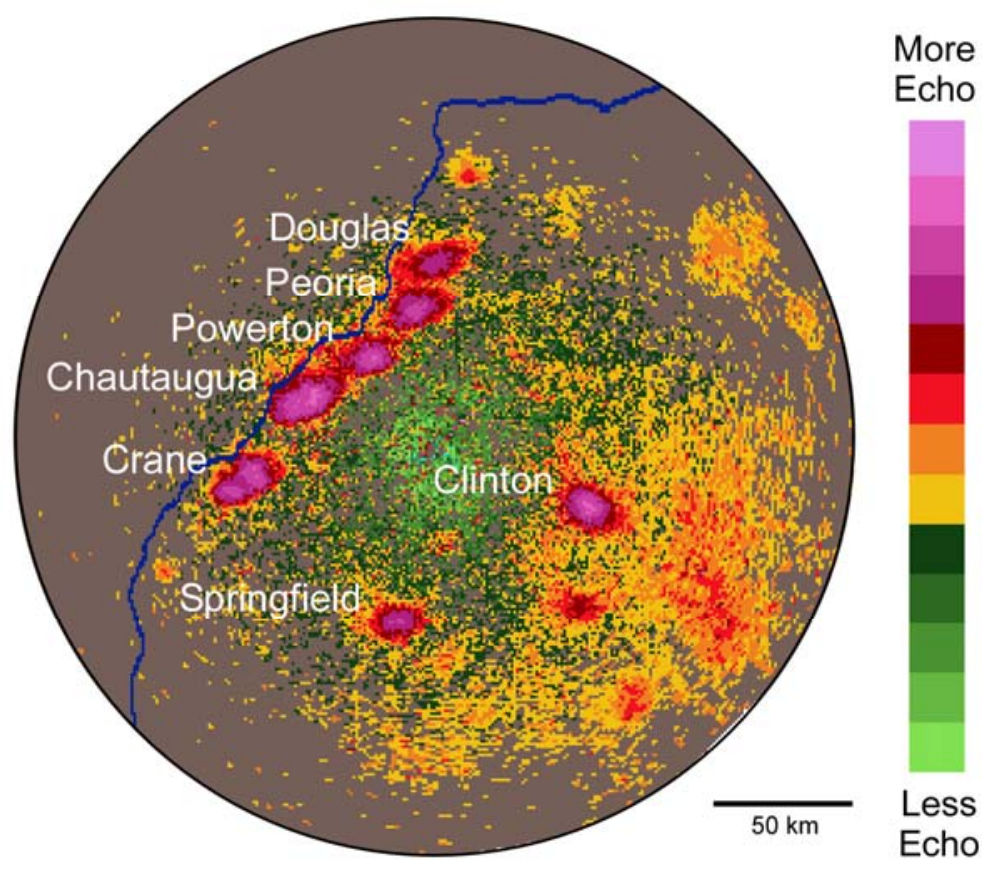

Figure 4. At the onset of migration, waterfowl depart cooling lakes (e.g., Clinton) and reservoirs along the Illinois River (e.g., Chautauqua NWR) at dusk (November 4, 2000, 5:54 p.m. CST). Known stopover habitats for waterfowl are labeled. By using these kinds of data, the relative use of different waterfowl stopover habitats can be comprehensively measured daily or seasonally. 


\section{A USGS/USFWS Collaboration}

In the past few years, efforts to advance the use of radar data to address bird conservation issues have arisen independently in several USGS/USFWS collaborations across the United States. Recently, the Principal Investigators from these projects have come together in a coalition of scientists and managers to coordinate radar-related research and to develop a suite of products for managers to use in the conservation of birds and bats. The goals of the collaboration among USGS, USFWS, and other partners are to identify migratory pathways and stopover sites for conservation, mitigation, and landscape-scale planning; communicate the importance of healthy landscapes and unobstructed airspaces for migrating wildlife; enable use of radar by the wider biological, wind power, and related communities; and simplify the analysis of radar data. The long-term focus is to use radar technologies to better understand movement patterns and habitat associations of migratory birds and other wildlife. Land managers and industry may use the knowledge and tools developed to optimize the siting of energy projects, other facilities, and migratory bird habitat projects.

This collaboration will provide a new, integrated science capability within USGS and the Department of the Interior (DOI) that will take advantage of the valuable biological data provided by the Doppler weather radar system and other radar technologies. In addition, it will ensure that research at various locations will be complementary, that scientists and managers will communicate regularly about research needs, methods, and results, and that there is a coordinated strategy for addressing conservation needs with radar data. The collaboration will enable the development of infrastructure, or the provision of such by partners, and will build the expertise required to retrieve, analyze, and interpret data from Doppler weather radars for conservation applications. It will facilitate the integration of multiple disciplines and areas of technical expertise including wildlife biology, landscape ecology, remote sensing, radar engineering, meteorology, software development, computer science, mapping, ecological modeling, artificial intelligence, and information technology and transfer. Implementation of this collaboration will position USGS and USFWS well to address their missions to provide the scientific information needed by resource managers (USGS) and to implement conservation and management, enforce laws, and issue permits for activities that affect migratory trust species (USFWS).

\section{Current USGS Research Using Radar Data}

There are currently several USGS scientists who have initiated or are developing research projects using radar data.

Dr. Janet Ruth (Arid Lands Field Station, Fort Collins Science Center, Albuquerque, NM), in collaboration with Dr. Robert Diehl (NSF Postdoctoral Fellow, University of Southern Mississippi [USM], Hattiesburg, MS), has worked with USFWS in developing a project to document landbird migration patterns and important stopover habitat in the borderlands of the Southwest (a region extending from Brownsville, TX to San Diego, CA). The project will use Doppler weather radar to map radar beam obstruction caused by topographic relief and to estimate geographic variation in migrant density, habitat associations of migrants (where possible), and variation in migrant flight altitude and direction of travel. This project is a high research priority for the USFWS Region 2 Migratory Bird Office and the Western Region of Partners in Flight.

Dr. Wylie Barrow (National Wetlands Research Center, Lafayette, LA) and Dr. Diehl have also initiated a series of collaborative studies using Doppler weather radar. In collaboration with NOAA, one project will aid in developing customized software and procedures needed to convert high resolution radar data into a form usable for subsequent analyses and georeferencing it for GIS 
applications. The project also includes a "proof of concept" component that will demonstrate the use of radar data to understand migrant densities and landscape-scale habitat use along Louisiana's imperiled coastal zone. A related project, developed in collaboration with the Gulf Coast Joint Venture, will determine broad habitat preferences of wintering waterfowl by monitoring daily waterfowl movements in southwest Louisiana. The project will combine data from direct visual observation, mobile marine radar, and radio-tagged mallards and pintails to corroborate patterns observed on Doppler weather radar. Researchers will then ascertain patterns of habitat use by large concentrations of waterfowl for roosting during the day (wildlife refuges) and feeding during the night (nearby agricultural rice fields). Results will be useful in documenting regional waterfowl feeding ecology, particularly spatiotemporal habitat use while wintering in southwest Louisiana, and will help refuge managers understand waterfowl use of the landscape within which the refuges are located.

Dr. Richard Sojda (Northern Rocky Mountain Science Center, Bozeman, MT), also in collaboration with Dr. Diehl and computer scientists at Montana State University, is developing a project that will build intelligent algorithms to identify radar echoes caused by migrating birds. If successful, such algorithms will provide a valuable, general purpose capability by allowing automated data mining of the Doppler weather radar archive. This capability in turn reduces reliance on experienced radar data interpreters and expedites the otherwise extremely time consuming process of identifying bird echoes by eye. The digital signatures developed will be used to delineate, validate, and map migration patterns across the landscape. Artificial intelligence methodologies developed in this project might eventually be used to assess the impacts of wind turbines on bird mortality. The project's long-term goal is to work with DOI agencies and the wind power industry to develop decision support systems focused on: (1) minimizing bird mortalities from obstructions, and (2) optimizing the conservation and management of migratory bird corridors and stopovers in relation to landscape habitat parameters.

Deanna Dawson (Patuxent Wildlife Research Center, Laurel, MD) and Dr. Tim Jones (USFWS, Atlantic Coast Joint Venture) are developing a multiyear, collaborative, regional study of the spatial and temporal distribution patterns and flight characteristics of birds and bats that migrate nocturnally through the Appalachian Mountain region of the mid-Atlantic States. The study will use Doppler weather radar data to provide a broad-scale view of migration through the region. Portable marine radar and acoustical monitoring techniques will be used to document site-specific passage rates, species relative abundance, and flight direction and altitudes of migrating birds and bats during fall and spring. This information will be used to model the effects of weather, site and landscape characteristics, and other variables on migrant abundance and flight characteristics to identify where, when, and under what conditions migrants may be at risk from wind power development in the region. Ms. Dawson is also an investigator (with Dr. Sarah Mabey, North Carolina State University, Dr. Bryan Watts, College of William and Mary, and Barry Truitt, The Nature Conservancy) in a study that uses data from Doppler weather radar and a new National Aeronautics and Space Administration (NASA) research Doppler radar to identify stopover sites in the Lower Chesapeake Bay region used by migrating passerines in fall.

Two additional projects are under development. Dr. Paul Cryan (Fort Collins Science Center, Fort Collins, CO) is collaborating with Dr. Diehl on a chapter regarding technologies for studying migrating bats. Dr. Susan Skagen (Fort Collins Science Center, Fort Collins, CO) is also collaborating with Dr. Diehl to determine whether shorebirds departing from the prairie potholes can be identified by using Doppler weather radar.

The Principal Investigators of these projects are working together to ensure that radarrelated research in USGS is coordinated and complementary under a broad umbrella effort developed in conjunction with land management and research partners and peers. Although the 
projects are being conducted in specific regions of the country, the results will be of broader application and use. Following are some examples of how these projects will contribute to and merge together into a larger picture of bird migration and the applications of radar technologies. Dr. Ruth's project will result in additional information about how to deal with topographic obstructions (e.g., mountains) of radar beams in other mountainous regions. It may also result in the development of methods to estimate the altitude of birds during migration. Dr. Barrow's project will help to develop software that will be made available to all users of the Doppler weather radar data archive. More immediately, it will be used by Dr. Sojda in identifying birds' distinctive Doppler weather radar attributes that will be used to "train" intelligent algorithms. In much the same way, the results of Dr. Sojda's work with artificial intelligence will facilitate all current USGS projects, as well as future ornithological applications of Doppler weather radar. Ms. Dawson's results will improve our understandings of the migratory behavior of birds and bats and can be applied and/or tested in other parts of the country. Collectively, these projects will demonstrate the use of radar data in understanding the movements of migratory birds (passerines, shorebirds, waterfowl, raptors) and bats. As a result, the broad coordination of these projects will result in substantial improvements in how we use radar technologies to understand bird and bat migration and how we address conservation issues in the future.

The collaboration is new and will benefit from the participation of additional partners, including other management agencies with similar needs (e.g., Bureau of Land Management, NOAA) and other scientists conducting radar-related research. Although some of the projects mentioned above have successfully acquired funding, substantial additional funds are required to fully support these projects and new research efforts. Coordinated, full funding within DOI and from other potential partners (e.g., NOAA, USDA Forest Service, state wildlife agencies, conservation organizations, and even the telecommunications and wind power industries) is vital to this effort. It is needed to move our fledgling science towards truly productive collaboration, to build and strengthen the needed scientific capabilities within USGS to conduct this work, and to develop the scientific information needed to further our knowledge of migration and to address the conservation needs of birds and bats.

\section{What Does the Future Hold?}

The information presented in this paper offers an overview of the current situation that has resulted in this collaboration--the conservation needs, the opportunities provided by radar technology applications, and the current projects initiated through USGS/USFWS collaborations. Future conservation needs and future opportunities for applying radar technology to conservation issues, however, are far broader than could be presented in this document.

- Global change biology: The radar data archive is growing (up to 13 years at present) as climate change is accelerating. Historical radar data may improve our understanding of wide ranging behavioral and ecological responses to changing climate that have implications for wildlife conservation and management. These include: (1) changes in seasonal temporal migration patterns (e.g., earlier in spring, later in fall); (2) changes in spatial migration patterns; or (3) changes in bird numbers.

- Response to weather: A long scientific history documents the response of migrating birds to weather, but the availability of data from systems like Doppler weather radar will enable a more detailed examination of this topic. For example, biologists have had some success in using it to predict migratory bird "fall outs" in response to weather and to document the consequences of migration over barriers during severe weather. 
- Migrant response to other landscape characteristics (beyond landcover type): Radar data may have applications in understanding response to patch core area, interpatch distances, different landscape matrices, or patch orientation.

- Migrant response to barriers

- Assessing the effectiveness of large scale management practices: For example, radar data may have applications in evaluating the efficacy of habitat restoration efforts at the landscape scale.

- Global applications of Doppler weather radar technologies: The techniques being developed now can be applied to other weather radars around the world. Both Mexico and Canada, for example, have weather surveillance radar systems.

- Validating weather radar: There are many opportunities for coordinating efforts to "truth" weather radar and further corroborate interpretations.

- Public outreach: There are many high-visibility opportunities to promote public awareness of and support for bird and bat conservation through radar-related avenues (e.g., local television or weather channel broadcasts showing real-time migration events or mobile radars traveling the country to document and study migration biology and raise local awareness).

- Further advances in Doppler weather radar technology: Increases in available products and resolution will result in: (1) better algorithms designed to differentiate among targets (perhaps with better taxonomic resolution); (2) more precise habitat-migrant associations; and (3) detection of a wider range of behaviors (e.g., changes in orientation in response to barriers, changes in latitude, or corrective migratory flights).

\section{- Applications to migratory insects}

The list provided above (not in priority order or comprehensive by any means) presents some of the opportunities that have been identified for the future. 


\section{Suggested Reading List}

Bruderer, B., 1997, The study of bird migration by radar, Part 1: The technical basis: Naturwissenschaften, v. 84, p. 1-8.

Bruderer, B., 1997, The study of bird migration by radar, Part 2: Major achievements: Naturwissenschaften, v. 84, p. 45-54.

Crum, T., Evancho, C., Horvat, C., Istok, M., and Blanchard, W., 2003, An update on NEXRAD program plans for collecting and distributing WSR-88D base data in near real time: 19th International Conference on Interactive Information Processing Systems (IIPS) for Meteorology, Oceanography, and Hydrology, Long Beach, California, American Meteorological Society.

Del Greco, S.A., and Hall, A., 2003, NCDC the "One Stop Shop" for all WSR-88D Level II data services: 19th International Conference on Interactive Information Processing Systems (IIPS) for Meteorology, Oceanography, and Hydrology, Long Beach, California, American Meteorological Society.

Diehl, R.H. and Larkin, R.P., in press, Introduction to the WSR-88D (NEXRAD) for ornithological research, Bird conservation implementation and integration in the Americas, in Ralph, C.J., and Rich, T.D., eds.: Proceedings of the Third International Partners in Flight Conference, U.S. Department of Agriculture Forest Service, GTR-PSW-xxx, Albany, California.

Diehl, R., 2003, Landscape associations of birds during migratory stopover: University of Illinois, Champaign-Urbana, Ph.D. dissertation, Department of Ecology, Ethology, and Evolution, 142 p.

Diehl, R.H., Larkin, R.P., and Black, J.E., 2003, Radar observations of bird migration over the Great Lakes: Auk, v. 120, p. 278-290.

Eastwood, E., 1967, Radar ornithology: London, Methuen.

Gauthreaux, Jr., S.A., and Belser, C.G., 2003, Radar ornithology and biological conservation: Auk, v. 120, p. 266-277.

Gauthreaux, Jr., S.A., and Belser, C.G., 2003, Bird movements on Doppler weather surveillance radar: Birding, v. 35, p. 616-628.

Gauthreaux, Jr., S.A., and Belser, C.G., 1998, Displays of bird movements on the WSR-88D: patterns and quantification: Weather and Forecasting, v. 13, p. 453-464.

Gauthreaux, Jr., S.A., Belser, C.G., and Van Blaricom, D., 2003, Using a network of WSR-88D weather surveillance radars to define patterns of bird migration at large spatial scales, in Berthold, P., Gwinner, E., and Sonnenschein, E., eds.: Avian migration, p. 335-346.

Gauthreaux, Jr., S.A., Mizrahi, D.S., and Belser, C.G., 1998, Bird migration and bias of WSR-88D wind estimates: Weather and Forecasting, v. 13, p. 465-481.

Larkin, R.P., in press, Radar techniques for wildlife: Techniques for Wildlife Investigations and Management (6th ed.), Wildlife Society.

Larkin, R.P., and Diehl, R.H., in press, Spectral width of birds and insects on pulsed Doppler radar: IEEE Transactions on Geoscience and Remote Sensing.

Larkin, R.P., Evans, W.R., and Diehl, R.H., 2002, Nocturnal flight calls of Dickcissels and Doppler radar echoes over south Texas in spring: Journal of Field Ornithology, v. 73, p. 2-8.

Russell, K.R., Mizrahi, D.S., and Gauthreaux, S.A., Jr., 1998, Large-scale mapping of Purple Martin pre-migratory roosts using WSR-88D weather surveillance radar: Journal of Field Ornithology, v. 69, p. 316-325. 


\section{Contacts}

\section{USGS}

Rick Kearney, USGS Headquarters, Reston, VA rkearney@usgs.gov

Wylie Barrow, USGS National Wetlands Research Center, Lafayette, LA wylie_barrow@usgs.gov Janet Ruth, USGS Fort Collins Science Center, Albuquerque, NM janet_ruth@usgs.gov

Richard Sojda, USGS Northern Rocky Mountain Science Center, Bozeman, MT sojda@usgs.gov Deanna Dawson, USGS Patuxent Wildlife Research Center, Laurel, MD ddawson@usgs.gov

\section{USFWS}

Albert Manville, USFWS Headquarters, Arlington, VA albert_manville@fws.gov

Michael Green, USFWS Region 1, Portland, OR michael_green@fws.gov

David Krueper, USFWS Region 2, Albuquerque, NM dave_krueper@fws.gov

Tom Will, USFWS Region 3, Fort Snelling, MN tom_will@fws.gov

Dean Demarest, USFWS Region 4, Atlanta, GA dean_demarest@fws.gov

Scott Johnston, USFWS Region 5, Hadley, MA scott_johnston@fws.gov

Stephanie Jones, USFWS Region 6, Denver, CO stephanie_jones@fws.gov

\section{University Collaborator}

Robb Diehl, University of Southern Mississippi, Hattiesburg, MS Robert.diehl@usm.edu

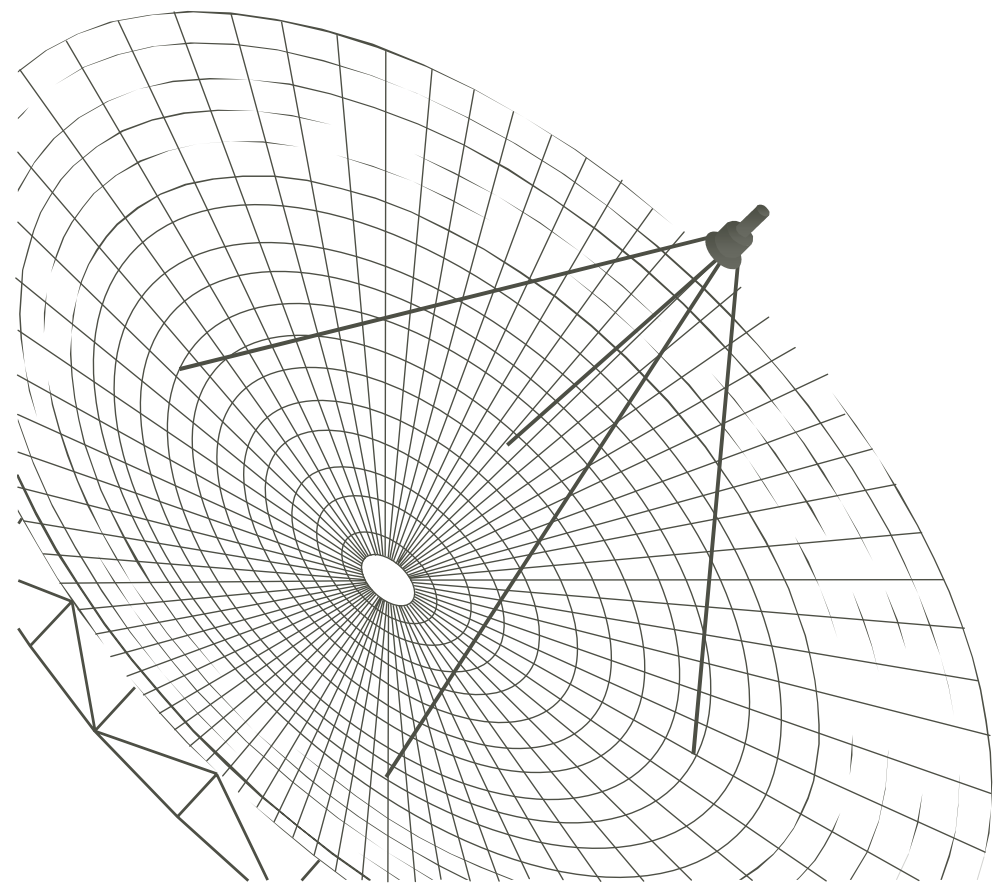

